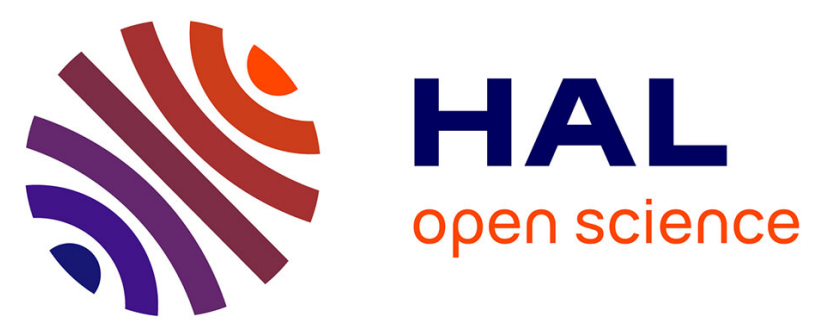

\title{
The genomic legacy from the extinct Lepus timidus to the three hare species of Iberia: contrast between mtDNA, sex chromosomes and autosomes
}

José Melo-Ferreira, Paulo C. Alves, Helder Freitas, Nuno Ferrand, Pierre Boursot

\section{To cite this version:}

José Melo-Ferreira, Paulo C. Alves, Helder Freitas, Nuno Ferrand, Pierre Boursot. The genomic legacy from the extinct Lepus timidus to the three hare species of Iberia: contrast between mtDNA, sex chromosomes and autosomes. Molecular Ecology, 2009, 18 (12), pp.2643-2658. 10.1111/j.1365294X.2009.04221.x . hal-02348046

\section{HAL Id: hal-02348046 \\ https://hal.umontpellier.fr/hal-02348046}

Submitted on 31 Jan 2022

HAL is a multi-disciplinary open access archive for the deposit and dissemination of scientific research documents, whether they are published or not. The documents may come from teaching and research institutions in France or abroad, or from public or private research centers.
L'archive ouverte pluridisciplinaire HAL, est destinée au dépôt et à la diffusion de documents scientifiques de niveau recherche, publiés ou non, émanant des établissements d'enseignement et de recherche français ou étrangers, des laboratoires publics ou privés. 


\title{
The genomic legacy from the extinct Lepus timidus to the three hare species of Iberia: contrast between mtDNA, sex chromosomes and autosomes
}

\author{
J. MELO-FERREIRA,${ }^{*}+\ddagger$ P. C. ALVES,${ }^{*}+$ H. FREITAS,$*$ N. FERRAND*† and P. BOURSOT \\ ${ }^{*}$ CIBIO, Centro de Investigação em Biodiversidade e Recursos Genéticos, Universidade do Porto, Campus Agrário de Vairão, 4485-661 \\ Vairão, Portugal, +Departamento de Zoologia e Antropologia, Faculdade de Ciências da Universidade do Porto, Rua do Campo Alegre, \\ s/n, 4169-007 Porto, Portugal, łUniversité Montpellier 2 (CNRS UMR5554), Institut des Sciences de l'Evolution, Case Courier 063, \\ 34095 Montpellier cedex 5, France
}

\begin{abstract}
Extensive interspecific genetic introgression is often reported, and appraising its genomic impact can serve to determine whether it results from selection on specific loci or from demographic processes affecting the whole genome. The three species of hares present in the Iberian Peninsula harbour high frequencies of mitochondrial DNA (mtDNA) from Lepus timidus, an arctic/boreal species now extinct in the region. This could result from the invasive replacement of $L$. timidus by the temperate species during deglaciation but should then have left traces in the nuclear genome. We typed single nucleotide polymorphisms (SNPs) discovered by sequencing 10 autosomal loci, two X-linked and one Y-linked in species-wide samples of the four taxa. Based on lineage-diagnostic SNPs, we detected no trace of L. timidus sex chromosomes in Iberia. From the frequencies of inferred haplotypes, autosomal introgression into $L$. granatensis appeared mostly sporadic but always widespread instead of restricted to the north as mtDNA. Autosomal introgression into Iberian L. europaeus, inhabiting the Pyrenean foothills, was hardly detectable, despite quasifixation of L. timidus mtDNA. L. castroviejoi, endemic to the Cantabrian Mountains and fixed for L. timidus mtDNA, showed little traces of autosomal introgression. The absence of sex-chromosome introgression presumably resulted from X-linked hybrid male unfitness. The contrasting patterns between the autosomes and mtDNA could reflect general gender asymmetric processes such as frequency-dependent female assortative mating, lower mtDNA migration and higher male dispersal, but adaptive mtDNA introgression cannot be dismissed. Additionally, we document reciprocal introgression between L. europaeus and both L. granatensis in Iberia and L. timidus outside Iberia.
\end{abstract}

Keywords: autosome, hybridization, introgression, Lepus, mtDNA, sex chromosomes

\section{Introduction}

Patterns of genetic variation in natural populations contain information on the evolutionary processes that have marked past species history and are thus of great interest to evolutionary biologists. A challenge of population genetics is to take apart the effects of demographic history and natural selection, which can be confounded when they leave similar traces on the coalescence and distribution patterns of alleles. One of the most efficient ways to take them apart is to contrast variation patterns across unlinked regions of the genome, because demography is expected to affect the whole genome similarly (although with potential deviations due to drift and differences in modes of transmission) while selection should affect only the targeted genomic regions. A number of population genetics tests of neutrality are based on this comparative principle (e.g. Nielsen 2005 for a review). 
Genetic introgression among species is typically a situation in which this question recurrently arises. The accumulation of reported cases of interspecific hybridization and introgression in all types of organisms reinforces the interest for the question of the evolutionary determinants and adaptive consequences of the phenomenon (Arnold et al. 2008). However, in many cases, documentation of introgression is limited to a single marker, most often mitochondrial DNA (mtDNA) in animals. It has been argued that mtDNA was especially prone to interspecific exchanges based on the frequent observation of such cases and some evolutionary explanations for this pattern have been proposed (Takahata \& Slatkin 1984; Chan \& Levin 2005; Currat et al. 2008). In the absence of comparison with other genomic regions or of direct evidence for fitness effects, however, it appears generally difficult to decide for any given study case whether introgression was adaptive or accidental, no matter how extensive and spectacular it may be. Relatively few studies have attempted to either compare extensively mtDNA with other markers, or to gather external evidence of the conditions under which mtDNA introgression could have occurred (e.g. Tosi et al. 2000; Pidancier et al. 2006; McGuire et al. 2007; Gompert et al. 2008; Pilkington et al. 2008; Plotner et al. 2008), but most studies have concluded that mtDNA contrasted with the nuclear genome, and in several instances that mtDNA introgression was selectively favoured.

Here we assess the level of introgression at markers on the $\mathrm{X}, \mathrm{Y}$ and autosomes in a previously described situation of massive mtDNA introgression in hares in Iberia (Alves et al. 2003; Melo-Ferreira et al. 2005, 2007). The Iberian Peninsula hosts three of the five hare species naturally occurring in Europe. Lepus granatensis, the Iberian hare, occupies most of the Peninsula while the broom hare, L. castroviejoi, prevails in the Cantabrian Mountains, and the Pyrenean foothills are inhabited by the brown hare, L. europaeus, whose range further extends throughout temperate Europe (Fig. 1). The mountain hare, L. timidus, is found in the northern Palaearctic, from the British Isles to the Russian Far East, and also as isolates in the Alps, Poland and Japan (Angerbjörn \& Flux 1995). The latter represent relicts of the past distribution of this arctic-boreal species, the most widespread hare species in Europe during the last glacial period according to palaeontological records (Lopez-Martinez 1980). Patterns of genetic variation over the present range of L. timidus, both for mtDNA (MeloFerreira et al. 2007) or microsatellites (Hamill et al. 2006), are compatible with a past expansion and continuous distribution south of the ice rim. This expansion once extended as far south as the Iberian Peninsula, as attested by both palaeontological data (Altuna 1970) and traces of ancient hybridization with hare species endemic of Iberia. In fact, in Northern Iberia, all populations of the three hare species presently occurring in the Peninsula were found to harbour high frequencies of mitochondrial DNA lineages of L. timidus origin (Alves et al. 2003; Melo-Ferreira et al. 2005, 2007) (Fig. 1). mtDNA of L. timidus origin is almost fixed in the Pyrenean range of L. europaeus, and very frequent in the northern half of the peninsula for L. granatensis. $L$. castroviejoi displays two mtDNA lineages, one closely related to those introgressed in the other species, and a second one that has formerly been suggested to also be of L. timidus origin (Alves et al. 2003, 2008a).

Melo-Ferreira et al. (2007) previously proposed that this massive introgression of mtDNA occurred during the competitive replacement of the arctic species by the temperate ones as climate became warmer at the end of the last glaciation. Here we report the complete absence of introgression for one $\mathrm{Y}$ and two $\mathrm{X}$ chromosome markers and the generally rare but always geographically widespread introgression of L. timidus origin at 10 autosomal loci in the Iberian Peninsula. We argue that for these findings to be compatible with the competitive replacement hypothesis, some general and gender-asymmetric biological process must have been operating.

\section{Materials and methods}

\section{Biological samples}

Specimens of four Lepus species of hares, L. granatensis, L. europaeus, L. castroviejoi and L. timidus, from 37 sample locations in Europe and Asia were used in this study (Table 1; Fig. 1). Total genomic DNA was extracted from frozen liver or ear tissue using standard methods similar to those described by Sambrook et al. (1989). Maleness was determined by the successful amplification of the SRY gene.

\section{Sequencing}

Fragments of 10 loci (Table 1) were amplified in six specimens of each of the four species using the primers depicted in Table S1, Supporting information. All these loci are known to be autosomal in humans and mice, and some are known to be likewise in rabbit (e.g. ALB and TF; Chantry-Darmon et al. 2003). We assumed that such was the case in hares. The polymerase chain reaction (PCR) products were sequenced using the forward and reverse primers following the ABI PRISM BigDye Terminator Cycle Sequencing 3.1 standard protocol and an ABI PRISM 3130 sequencer (Applied Biosystems).

Fragments of the MSN, SMCX and SRY loci, were amplified in 48,48 and 78 male hare specimens, respectively (Table 1; primers and PCR conditions are depicted in Table S2, Supporting information). The two former loci are known to be X-linked and the latter Y-linked in human, mouse and rabbit, and thus, we assumed that such was 


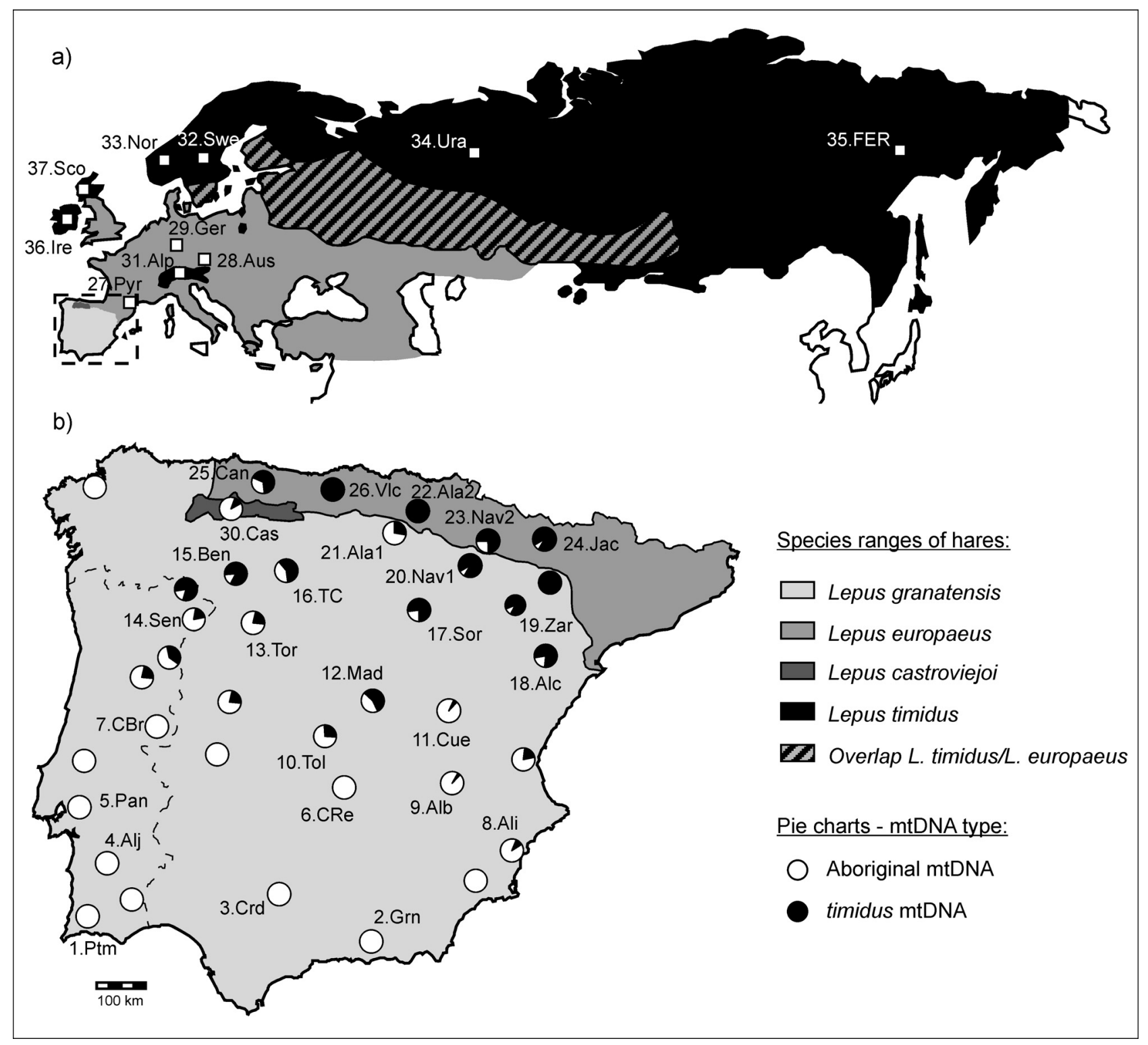

Fig. 1 Geographical distribution of Lepus granatensis, L. europaeus, L. castroviejoi and L. timidus in (a) Eurasia and (b) the Iberian Peninsula, according to Flux \& Angermann (1990) and Mitchell-Jones et al. (1999). The pie charts in (b) show the frequencies of mtDNA of L. timidus origin in Iberia (Melo-Ferreira et al. 2005; Alves et al. 2008b). Populations of the present study are given numbers and codes on both maps, according to Table 1 which gives sample sizes.

also the case in hares. While the reverse primers for the X-linked loci were original to this work, forward primers were from Geraldes et al. (2006). The SRY primers were designed based on a first L. granatensis SRY sequence produced using primers specific to the European rabbit (Geraldes et al. 2005). The PCR products were sequenced using the forward PCR primers and/or the sequencing reverse primers 5'-GGGAAGATAATGGGTAGTGAGTGG$3^{\prime}$ and $5^{\prime}$-CCTGCTCCTCCTTCATTAACTAGCATT-3' for the MSN and SMCX fragments, respectively, and using the sequencing primers 5'-ATCGAGTAACACTGGCTGC-3' and 5'-ATCATACCCATTGGTCGAG-3' for the SRY fragment. Sequences were obtained using the sequencing protocol described above.

\section{$X$ and $Y$-linked loci sequence data analyses}

All sequences were visually inspected and aligned using ClustalW (Thompson et al. 1994). Since the X-linked loci were only sequenced in male specimens, haplotypes were recovered directly. The number of segregating sites, nucleotide polymorphism, and $\theta$ computed from the 


\begin{tabular}{|c|c|c|c|c|c|c|c|}
\hline \multirow[b]{2}{*}{ No. } & \multirow[b]{2}{*}{ Code } & \multirow[b]{2}{*}{ Locality } & \multicolumn{2}{|c|}{ Sequences } & \multicolumn{2}{|l|}{ SNaPshot } & \multirow{2}{*}{$\frac{\text { RFLP }}{\text { SRY }}$} \\
\hline & & & $X^{*}$ & SRY & Autosomest & $\mathrm{X}^{*}$ & \\
\hline \multicolumn{3}{|c|}{ Lepus granatensis } & 21 & 30 & 239 & 241 & 184 \\
\hline 1 & Ptm & Portimão, Portugal & 2 & 2 & 10 & 10 & 4 \\
\hline 2 & Grn & Granada, Spain & 2 & 7 & 12 & 12 & 14 \\
\hline 3 & Crd & Cordoba, Spain & 2 & 3 & 12 & 12 & 5 \\
\hline 4 & $\mathrm{Alj}$ & Aljustrel, Portugal & & 9 & 9 & 9 & 10 \\
\hline 5 & Pan & Pancas, Portugal & 2 & 3 & 12 & 12 & 11 \\
\hline 6 & $\mathrm{CRe}$ & Ciudad Real, Spain & 2 & & 12 & 12 & 11 \\
\hline 7 & $\mathrm{CBr}$ & Castelo Branco, Portugal & & 2 & 9 & 10 & 8 \\
\hline 8 & Ali & Alicante, Spain & & & 12 & 12 & 8 \\
\hline 9 & Alb & Albacete, Spain & & 1 & 12 & 12 & 13 \\
\hline 10 & Tol & Toledo, Spain & 1 & & 12 & 12 & 4 \\
\hline 11 & Cue & Cuenca, Spain & 1 & & 12 & 12 & 10 \\
\hline 12 & Mad & Madrid, Spain & & 1 & 12 & 12 & 12 \\
\hline 13 & Tor & Tordesillas, Spain & & & 12 & 12 & 12 \\
\hline 14 & Sen & Sendim, Portugal & & & 12 & 12 & 4 \\
\hline 15 & Ben & Benavente, Spain & 1 & 1 & 11 & 11 & 8 \\
\hline 16 & $\mathrm{TC}$ & Tierra de Campos, Spain & 1 & & 12 & 12 & 8 \\
\hline 17 & Sor & Soria, Spain & 2 & & 12 & 12 & \\
\hline 18 & Alc & Alcañiz, Spain & 1 & & 12 & 12 & 8 \\
\hline 19 & Zar & Zaragoza, Spain & 1 & & 11 & 11 & 7 \\
\hline 20 & Nav1 & Navarra, Spain & 1 & & 9 & 10 & 2 \\
\hline 21 & Ala1 & Álava, Spain & 2 & 1 & 12 & 12 & 25 \\
\hline \multicolumn{3}{|c|}{ Lepus europaeus } & 17 & 22 & 75 & 79 & 44 \\
\hline 22 & Ala2 & Álava, Spain & 2 & 1 & 12 & 12 & 9 \\
\hline 23 & Nav2 & Navarra, Spain & 2 & & 5 & 7 & 1 \\
\hline 24 & Jac & Jaca, Spain & 2 & 1 & 7 & 8 & 3 \\
\hline 25 & Can & Cantabria, Spain & 2 & & 11 & 11 & 8 \\
\hline 26 & Vlc & Villarcayo, Spain & 2 & 1 & 12 & 12 & 9 \\
\hline 27 & Pyr & Eastern Pyrenees, France & 1 & 4 & 8 & 8 & \\
\hline 28 & Aus & Austria & 2 & 4 & 8 & 9 & \\
\hline 29 & Ger & Germany & 4 & 11 & 12 & 12 & 14 \\
\hline \multicolumn{3}{|c|}{ Lepus castroviejoi } & 2 & 2 & 9 & 9 & 2 \\
\hline 30 & Cas & Cordillera Cantabrica, Spain & 2 & 2 & 9 & 9 & 2 \\
\hline \multicolumn{3}{|c|}{ Lepus timidus } & 8 & 24 & 24 & 24 & 13 \\
\hline 31 & Alp & Alps & 1 & 4 & 13 & 13 & 4 \\
\hline 32 & Swe & Sweden & 3 & 6 & 11 & 11 & 9 \\
\hline 33 & Nor & Norway & 2 & 2 & & & \\
\hline 34 & Ura & Urals, Russia & 1 & 2 & & & \\
\hline 35 & FER & Far East Russia & 1 & 7 & & & \\
\hline 36 & Ire & Ireland & & 2 & & & \\
\hline 37 & Sco & Scotland & & 1 & & & \\
\hline \multicolumn{3}{|c|}{ Total } & 48 & 78 & 347 & 353 & 243 \\
\hline
\end{tabular}

Table 1 Sampled localities and final sample sizes per population for the different data sets

*MSN, SMCX; †ALB, CA2, DARC, HPX, KITLG, PRKCI, SPTBN1, TF, OXA1L, UCP2.

number of segregating sites were estimated using DnaSP 4.20 (Rozas et al. 2003). The conformation to a model of selective neutrality and population equilibrium was tested by calculating Tajima's D (Tajima 1989) and Fu's Fs (Fu 1997) and tested for significance with 5000 simulated samples using Arlequin 3.0 (Excoffier et al. 2005). Median-joining networks were computed using Network 4.5 (www.fluxustechnology.com).

\section{RFLP typing of the SRY lineages}

By comparing the SRY sequences, we predicted that restriction enzyme HpyCH4III (recognition site 5'-ACN'GT3'; New England Biolabs) would allow distinguishing the major lineages detected by sequencing. An SRY fragment (1308-1310 bp, including primers) was amplified in 243 hare specimens from the four species (Table 1; including 56 
of the sequenced individuals, which were positive controls), using the primers and PCR conditions depicted in Table S2. After digestion with $\mathrm{HpyCH} 4 \mathrm{III}$, the restriction patterns were revealed by electrophoresis on horizontal polyacrylamide gels (T9C5) and silver staining.

\section{SNP genotyping}

On the basis of the sequencing data, we selected single nucleotide polymorphisms (SNPs) whose alleles were frequent in the whole sample or at least in one of the four species. Forty-two SNPs and one insertion/deletion (indel, $23 \mathrm{bp}$ long) distributed across the 12 loci (10 autosomal and 2 X-linked) were genotyped in 252 L. granatensis, 85 L. europaeus, 10 L. castroviejoi and 29 L. timidus using the $\mathrm{SNaPshot}$ minisequencing ready reaction mix (Applied Biosystems). Each of the 12 loci was separately amplified for all specimens using primers and PCR conditions detailed in Table S3, Supporting information. All these primers are original to this work except the PRKCI reverse primer (Matthee et al. 2004) and the TF forward primer (Wallner et al. 2001). Three sets of PCR products were created for each specimen by mixing in equal proportions $-\operatorname{mix} 1$ : ALB, KITLG, OXA1L and SMCX; mix 2: DARC, PRKCI, TF, SMCX; mix 3: CA2, HPX, SPTBN1 and UCP2. Primers and unincorporated deoxynucleotides (dNTPs) were removed by incubation with ExoSAP-IT (USB).

Three sets of multiplex primer extension reactions (SNaPshot multiplexes 1, 2 and 3, corresponding to PCR mixes 1, 2 and 3, respectively; Table S3) were carried out in a total volume of $10 \mu \mathrm{L}$, containing $2 \mu \mathrm{L}$ of SNaPshot Ready Reaction mix, $3 \mu \mathrm{L}$ of the purified pooled PCR products and $1 \mu \mathrm{L}$ of pooled SNaPshot primers $(0.2 \mu \mathrm{M}$ per primer in the reaction solution). Given the occasional existence of polymorphism at the primer annealing sites, primers $6 \mathrm{D}$ and 9B were mixtures of several variants (6D1-4 and 9B1-2; Table S3). The SNaPshot primers were composed of a portion specific to the annealing location and of a 5 ' tail of arbitrary sequences with variable lengths, yielding non-overlapping locus-specific fragment lengths in each multiplex reaction. All SNaPshot primers were OliGold-purified (Eurogentec) in order to minimize incomplete synthesis products.

Thermal cycling for single base extension reactions were performed using 40 cycles of denaturation at $96^{\circ} \mathrm{C}$ for $10 \mathrm{~s}$, annealing at $50{ }^{\circ} \mathrm{C}$ for $5 \mathrm{~s}$ and extension at $60^{\circ} \mathrm{C}$ for $30 \mathrm{~s}$. The excess of fluorescence-labelled dideoxynucleotides (ddNTPs) was inactivated by incubation with Shrimp Alkaline Phosphatase (SAP; USB). Finally, $1.5 \mu \mathrm{L}$ of the SAP-treated products were mixed with $8.5 \mu \mathrm{L}$ of $\mathrm{Hi}$-Di formamide and $0.5 \mu \mathrm{L}$ of GeneScan 120 LIZ size standard (Applied Biosystems). The samples were separated by capillary electrophoresis in an ABI PRISM 3130 Genetic Analyser and data analysed using Peak Scanner version 1.0 (Applied Biosystems).
A 23-bp insertion/deletion in locus UCP2 was also genotyped in the same set of specimens using a direct PCR approach (primers are shown in Table S3). The differentsized alleles were revealed after agarose gel electrophoresis.

\section{SNP data analyses}

The information of the 34 SNPs and the insertion/deletion collected from the 10 autosomal loci were organized into locus-specific genotypes. Only individuals with a maximum of $10 \%$ of missing data (i.e. missing information of one out of 10 loci) were retained for subsequent analyses. Alleles at each locus were reconstructed using the Bayesian statistical method implemented in Phase version 2.1.1 (Stephens et al. 2001; Stephens \& Scheet 2005), which allows estimating the uncertainty associated with each phase call. Five replicates with different seed numbers were run for each locus to ensure the consistency of the phase determination. Each run consisted of a burn-in of 100 iterations followed by 1000 main iterations, each consisting of 10 steps through the Markov chain.

To assess whether this data set allowed discriminating the four hare species under study, a non-parametric three-dimension factorial correspondence analysis (3D-FCA) was performed using Genetix version 4.03 (Belkhir et al. 1996-2004).

Because the putative species discrimination using the FCA does not exclude the possibility of introgression among species, we also applied the individual genotype assignment method implemented in the software Structure version 2.2 (Pritchard et al. 2000). The proportion of the genotype of each individual that could be traced to each of the parent populations was estimated applying the admixture model with independent allele frequencies across these parent populations. For each locus, alleles were used as reconstructed by Phase version 2.1.1 (as shown in Table 2). Three separate runs of 200000 burn-in iterations followed by 2 million main iterations were performed. The number of populations (species) was set to four in all analyses. No prior information about the population of origin was given. The $95 \%$ posterior probability interval around each individual admixture proportion was computed, assessing the support for the putative cases of mixed ancestry.

The eight SNPs collected from the $X$-linked loci were also organized into locus-specific haplotypes on the basis of the genotypes of males.

\section{Results}

\section{Ten autosomal loci}

Based on the preliminary sequencing of each of the 10 autosomal loci (GenBank Accession nos FJ811557-FJ811821; 
Table 2 Haplotypes inferred from the SNP screening and their frequencies in the four species

\begin{tabular}{|c|c|c|c|c|c|c|c|c|c|c|c|c|c|}
\hline \multirow{3}{*}{$\frac{\text { Locus }}{1 \mathrm{ALB}}$} & & & \multicolumn{4}{|c|}{ Frequency per species } & \multirow{3}{*}{$\begin{array}{l}\text { Locus } \\
7 \text { SPTBN1 }\end{array}$} & & & \multicolumn{4}{|c|}{ Frequency per species } \\
\hline & \multicolumn{2}{|c|}{ Allele } & \multirow{2}{*}{$\frac{g r a}{0.992}$} & \multirow{2}{*}{$\begin{array}{l}\text { eur } \\
0.075\end{array}$} & \multirow[t]{2}{*}{ cas } & \multirow[t]{2}{*}{ tim } & & \multicolumn{2}{|c|}{ Allele } & \multirow{2}{*}{$\frac{g r a}{0.981}$} & \multirow[t]{2}{*}{ eur } & \multirow{2}{*}{$\begin{array}{l}\text { cas } \\
0.111\end{array}$} & \multirow[t]{2}{*}{ tim } \\
\hline & 1 & CCAT & & & & & & 1 & CAG & & & & \\
\hline & 2 & CTAT & & & & 0.125 & & 2 & GAG & 0.019 & 0.574 & & 1.000 \\
\hline & 3 & CTAC & 0.002 & 0.925 & & 0.021 & & 3 & GAA & & & 0.889 & \\
\hline & 4 & CTTT & & & 1.000 & & & 4 & GCG & & 0.426 & & \\
\hline & 5 & TTAT & 0.006 & & & 0.854 & $8 \mathrm{TF}$ & 1 & $\mathrm{CT}$ & 0.945 & 0.418 & 1.000 & 0.688 \\
\hline \multirow[t]{5}{*}{2 CA2 } & 1 & ATCA & 0.964 & & & & & 2 & CG & 0.055 & 0.007 & & 0.313 \\
\hline & 2 & ATCG & 0.006 & 0.096 & & 0.208 & & 3 & TT & & 0.575 & & \\
\hline & 3 & ATAG & & & 1.000 & & 9 OXA1L & 1 & ACA & 0.991 & & & \\
\hline & 4 & ACCG & 0.025 & 0.007 & & 0.771 & & 2 & CCA & 0.004 & 1.000 & & \\
\hline & 5 & GTCG & 0.004 & 0.897 & & 0.021 & & 3 & $\mathrm{CCT}$ & 0.004 & & & 0.974 \\
\hline \multirow[t]{5}{*}{3 DARC } & 1 & GACG & 0.998 & 0.027 & & & & 4 & CTA & & & 1.000 & \\
\hline & 2 & GCCG & 0.002 & 0.370 & & 0.458 & & 5 & CTT & & & & 0.026 \\
\hline & 3 & GCCA & & & & 0.542 & 10 UCP2 & 1 & $6 \mathrm{TCA}^{*}$ & 0.979 & 0.007 & 0.375 & \\
\hline & 4 & GCGG & & 0.027 & 1.000 & & & 2 & $6 \mathrm{TCG}^{*}$ & 0.002 & & & \\
\hline & 5 & ACCG & & 0.575 & & & & 3 & $5 \mathrm{TCA}^{*}$ & 0.006 & 0.081 & 0.063 & 0.354 \\
\hline \multirow[t]{4}{*}{4 HPX } & 1 & TTG & 0.975 & 0.324 & & 0.875 & & 4 & $5 \mathrm{TCG}^{*}$ & 0.013 & 0.912 & & 0.021 \\
\hline & 2 & TTA & & & & 0.083 & & 5 & $5 \mathrm{TGA}^{*}$ & & & & 0.625 \\
\hline & 3 & TCG & & & 1.000 & & & 6 & $5 \mathrm{GTA}^{*}$ & & & 0.563 & \\
\hline & 4 & ATG & 0.025 & 0.676 & & 0.042 & $11 \mathrm{MSN}+$ & 1 & TTGC & 1.000 & 0.018 & & \\
\hline \multirow[t]{7}{*}{5 KITLG } & 1 & CACG & 0.004 & 0.743 & & & & 2 & GCGC & & 0.927 & & \\
\hline & 2 & CACA & & 0.243 & & & & 3 & TCGC & & 0.055 & & 0.194 \\
\hline & 3 & CATG & & & 0.722 & & & 4 & TCGT & & & & 0.806 \\
\hline & 4 & CGCG & 0.987 & 0.007 & 0.278 & & & 5 & TCAC & & & 1.000 & \\
\hline & 5 & CGCA & & 0.007 & & & $12 \mathrm{SMCX}+$ & 1 & CCGT & 0.996 & 0.018 & & \\
\hline & 6 & TACG & 0.008 & & & 0.979 & & 2 & CTGC & 0.004 & 0.982 & & \\
\hline & 7 & TATG & & & & 0.021 & & 3 & CTAT & & & & 1.000 \\
\hline \multirow[t]{5}{*}{6 PRKCI } & 1 & GGCC & 0.344 & & & & & 4 & TTGT & & & 1.000 & \\
\hline & 2 & GGTC & 0.532 & 0.446 & & 0.354 & 13 SRY & A & $8 C^{*}$ & 1.000 & & 1.000 & \\
\hline & 3 & GGTA & 0.125 & & & 0.646 & & B & $7 G^{*}$ & & 1.000 & & \\
\hline & 4 & GATC & & 0.554 & & & & $\mathrm{C}$ & $8 \mathrm{G}^{*}$ & & & & 1.000 \\
\hline & 5 & AGTC & & & 1.000 & & & & & & & & \\
\hline
\end{tabular}

gra, Lepus granatensis; eur, Lepus europaeus; cas, Lepus castroviejoi; tim, Lepus timidus; *5, 23-bp insertion; 6, 23-bp deletion; 7, 2-bp insertion; 8, 2-bp deletion; +27 specimens with unknown sex were dismissed in the allele count (see Tables S17 and S18).

see Tables S4-S13, Supporting information, for a summary of observed variation), 34 SNPs and one 23-bp indel were genotyped (Table 2). After dismissing the information from the individuals with an excess of missing data, the genotypes of 347 specimens were retained for further analyses (239 L. granatensis, 75 L. europaeus, 9 L. castroviejoi and 24 L. timidus; Table 1). On this basis, we inferred 49 haplotypes whose frequencies in the four species are presented in Table 2. All phase calls presented a probability higher than $95 \%$. None of the loci was fully diagnostic of the four species but large haplotype frequency differences characterized the species. Accordingly, the 3D-FCA showed a perfect separation of the samples into four groups, corresponding to their species assignation based on their geographical origin (Fig. 2).

This does not, however, preclude that some of the allelesharing between species results from introgression. Because of the low number of SNPs typed per locus, it cannot be formally excluded that all shared alleles represent ancestrally shared polymorphisms. We will, however, attempt here to pinpoint situations where the combination of allele frequencies and geographical distributions make ancestral sharing most unlikely. Introgression between species is easier to detect when an allele is very frequent or is fixed in one species but is rare in another. We examined such possibilities, taking into account the geographical distribution of alleles, as detailed in Table 3, where the putative origin of alleles that presumably crossed the species' boundaries is also indicated (note that in this table, L. granatensis populations are ordered from southernmost to northernmost).

A large number of alleles are sporadic in L. granatensis, i.e. at low frequencies in several populations spread over Iberia, while frequent in L. timidus (ALB_5, CA2_4, KITLG_6, SPTBN1_2, OXA1L_3, TF_2, UCP2_3; Table 3). 
Table 3 Populations frequencies of the inferred haplotypes at 10 autosomal loci, and of mtDNA of Lepus timidus origin

\begin{tabular}{|c|c|c|c|c|c|c|c|c|c|c|c|c|c|c|c|c|c|c|c|c|c|c|c|c|c|c|c|c|c|c|c|c|c|c|c|c|c|c|c|c|c|c|c|}
\hline \multirow[b]{2}{*}{ Pop\# 1} & \multirow[b]{2}{*}{ Pop } & \multicolumn{4}{|l|}{ ALB } & \multicolumn{4}{|l|}{$\mathrm{CA} 2$} & \multicolumn{4}{|c|}{ DARC } & \multicolumn{3}{|l|}{ HPX } & \multicolumn{5}{|l|}{ KTLG } & \multicolumn{4}{|c|}{ PRKCI } & SPTBN & & & TF & & & OXA1I & & & & & UCP2 & & & & & & $\mathrm{mtDNA} \mathrm{A}^{*}$ \\
\hline & & 1 & 3 & 4 & 5 & 1 & 3 & 4 & 5 & 1 & 2 & 3 & 5 & 2 & 3 & 4 & 1 & 2 & 4 & 5 & 6 & 1 & 2 & 4 & 5 & 1 & 2 & 4 & 1 & 2 & 3 & 1 & 2 & 3 & 4 & 5 & 1 & 2 & 3 & 4 & 5 & 6 & timidus \\
\hline L. grat & natensis & & & & & & & & & & & & & & & & & & & & & & & & & & & & & & & & & & & & & & & & & & \\
\hline 1 & Ptm & 1.00 & & & & 0.95 & & $0.05^{t}$ & & 1.00 & & & & 1.00 & & & & & 1.00 & & & 0.20 & $\begin{array}{lll}0.70 & 0.1\end{array}$ & & & 1.00 & & & 1.00 & & & 1.00 & & & & & 1.00 & & & & & & \\
\hline 2 & Grn & 1.00 & & & & 1.00 & & & & 1.00 & & & & 1.00 & & & & & 1.00 & & & 0.41 & $\begin{array}{lll}0.32 & 0.2\end{array}$ & & & 1.00 & & & 1.00 & & & 1.00 & & & & & 1.00 & & & & & & \\
\hline 3 & Crd & 1.00 & & & & 1.00 & & & & 1.00 & & & & 1.00 & & & & & 1.00 & & & 0.33 & $\begin{array}{lll}0.54 & 0.1\end{array}$ & & & 1.00 & & & 1.00 & & & 1.00 & & & & & 0.96 & & $0.04^{t}$ & & & & \\
\hline 4 & Alj & 1.00 & & & & 1.00 & & & & 1.00 & & & & 1.00 & & & & & 1.00 & & & & 1.00 & & & 1.00 & & & 1.00 & & & 1.00 & & & & & 1.00 & & & & & & \\
\hline 5 & Pan & 0.96 & & & $0.04^{t}$ & 0.83 & & $0.17^{t}$ & & 1.00 & & & & 1.00 & & & & & 1.00 & & & 0.54 & $\begin{array}{lll}0.33 & 0.1\end{array}$ & & & 1.00 & & & 1.00 & & & 1.00 & & & & & 1.00 & & & & & & \\
\hline 6 & CRe & 1.00 & & & & 0.92 & & $0.08^{t}$ & & 1.00 & & & & 1.00 & & & & & 1.00 & & & 0.29 & $\begin{array}{ll}0.63 & 0.0\end{array}$ & & & 0.96 & $0.04^{t}$ & & 0.79 & $0.21^{t}$ & & 1.00 & & & & & 1.00 & & & & & & \\
\hline 7 & $\mathrm{CBr}$ & 0.89 & & & $0.11^{t}$ & 1.00 & & & & 1.00 & & & & 1.00 & & & & & 0.94 & & $0.06^{\mathrm{t}}$ & 0.61 & 0.39 & & & 1.00 & & & 1.00 & & & 1.00 & & & & & 0.94 & & $0.06^{t}$ & & & & \\
\hline 8 & Ali & 1.00 & & & & 1.00 & & & & 1.00 & & & & 1.00 & & & & & 1.00 & & & 0.33 & $\begin{array}{lll}0.25 & 0.4\end{array}$ & & & 1.00 & & & 0.96 & $0.04^{t}$ & & 1.00 & & & & & 1.00 & & & & & & 0.10 \\
\hline 9 & Alb & 1.00 & & & & 1.00 & & & & 1.00 & & & & 1.00 & & & & & 1.00 & & & 0.33 & $\begin{array}{lll}0.50 & 0.1\end{array}$ & & & 0.960 & $0.04^{t}$ & & 0.92 & $0.08^{t}$ & & 1.00 & & & & & 1.00 & & & & & & 0.04 \\
\hline 10 & Tol & 1.00 & & & & 1.00 & & & & 1.00 & & & & 1.00 & & & & & 1.00 & & & 0.25 & 0.540 .2 & & & 0.92 & $0.08^{t}$ & & 0.87 & $0.13^{t}$ & & 1.00 & & & & & 1.00 & & & & & & 0.27 \\
\hline 11 & Cue & 1.00 & & & & 1.00 & & & & 1.00 & & & & 1.00 & & & & & 1.00 & & & 0.33 & $\begin{array}{lll}0.42 & 0.2\end{array}$ & & & 1.00 & & & 0.96 & $0.04^{t}$ & & 0.92 & & $0.08^{t}$ & & & 1.00 & & & & & & 0.05 \\
\hline 12 & Mad & 1.00 & & & & 1.00 & & & & 1.00 & & & & 1.00 & & & & & 0.96 & & $0.04^{t}$ & 0.63 & $\begin{array}{lll}0.33 & 0.0\end{array}$ & & & 1.00 & & & 1.00 & & & 1.00 & & & & & 1.00 & & & & & & 0.56 \\
\hline 13 & Tor & 1.00 & & & & 0.96 & & $0.04^{t}$ & & 1.00 & & & & 1.00 & & & & & 1.00 & & & 0.29 & $\begin{array}{ll}0.63 & 0.0\end{array}$ & & & 1.00 & & & 0.92 & $0.08^{t}$ & & 1.00 & & & & & 1.00 & & & & & & 0.23 \\
\hline 14 & Sen & 1.00 & & & & 0.96 & & $0.04^{t}$ & & 1.00 & & & & 1.00 & & & & & 1.00 & & & 0.25 & $\begin{array}{lll}0.62 & 0.1\end{array}$ & & & 0.96 & $0.04^{t}$ & & 1.00 & & & 1.00 & & & & & 1.00 & & & & & & 0.19 \\
\hline 15 & Ben & 1.00 & & & & 1.00 & & & & 1.00 & & & & 1.00 & & & & & 0.91 & & $0.09^{t}$ & 0.32 & $\begin{array}{lll}0.50 & 0.1\end{array}$ & & & 0.95 & $0.05^{t}$ & & 1.00 & & & 1.00 & & & & & 0.96 & & $0.05^{t}$ & & & & 0.84 \\
\hline 16 & TC & 1.00 & & & & 0.96 & & $0.04^{t}$ & & 1.00 & & & & 1.00 & & & & & 1.00 & & & 0.32 & $\begin{array}{lll}0.41 & 0.2\end{array}$ & & & 0.96 & $0.04^{t}$ & & 0.92 & $0.08^{t}$ & & 1.00 & & & & & 1.00 & & & & & & 0.59 \\
\hline 17 & Sor & 1.00 & & & & 1.00 & & & & 1.00 & & & & 1.00 & & & & & 1.00 & & & 0.42 & 0.58 & & & 1.00 & & & 0.96 & $0.04^{t}$ & & 1.00 & & & & & 1.00 & & & & & & 0.77 \\
\hline 18 & Alc & 1.00 & & & & 1.00 & & & & 1.00 & & & & 1.00 & & & & & 1.00 & & & 0.33 & 0.67 & & & 1.00 & & & 0.79 & $0.21^{t}$ & & 1.00 & & & & & 1.00 & & & & & & 0.79 \\
\hline 19 & Zar & 1.00 & & & & 0.95 & & $0.05^{t}$ & & 1.00 & & & & 1.00 & & & & & 1.00 & & & 0.09 & $\begin{array}{lll}0.82 & 0.0\end{array}$ & & & 1.00 & & & 1.00 & & & 1.00 & & & & & 1.00 & & & & & & 0.89 \\
\hline 20 & Nav1 & 1.00 & & & & 0.94 & & $0.06^{t}$ & & 1.00 & & & & 0.94 & & $0.06^{e}$ & & & 1.00 & & & 0.50 & 0.50 & & & 1.00 & & & 0.83 & $0.17^{t}$ & & 1.00 & & & & & 0.88 & 0.06 & & $0.06^{\mathrm{e}}$ & & & 0.96 \\
\hline 21 & Ala1 & 0.96 & $0.04^{\circ}$ & & & 0.880 .0 & & & $0.08^{e}$ & 0.96 & $0.04^{\mathrm{e}}$ & & & 0.45 & & $0.55^{e}$ & $0.08^{e}$ & & 0.92 & & & 0.42 & 0.58 & & & 0.92 & $0.08^{t}$ & & 0.96 & $0.04^{t}$ & & 0.920 & $0.08^{e}$ & & & & 0.79 & & & $0.21^{e}$ & & & 0.36 \\
\hline L. eurc & opaeus (1) & (Iberian) & & & & & & & & & & & & & & & & & & & & & & & & & & & & & & & & & & & & & & & & & \\
\hline 22 & $\mathrm{Ala} 2$ & $0.08^{8}$ & 0.92 & & & 0.0 & & & 0.96 & $0.04^{8}$ & 0.54 & & $\begin{array}{lll}0.17 & 0.25\end{array}$ & 0.38 & & 0.62 & 0.79 & 0.17 & $0.04^{8}$ & & & & 0.54 & 0.46 & & & 0.58 & 0.42 & 0.38 & & 0.62 & & 1.00 & & & & $0.08^{8}$ & & & 0.92 & & & 1.00 \\
\hline 23 & Nav2 & & 1.00 & & & & & & 1.00 & $0.20^{8}$ & 0.40 & & 0.40 & 0.20 & & 0.80 & 0.90 & 0.10 & & & & & 0.30 & 0.70 & & & 0.50 & 0.50 & 0.30 & & 0.70 & & 1.00 & & & & & & & 1.00 & & & 0.75 \\
\hline 24 & $\mathrm{Jac}$ & $0.21^{8}$ & 0.79 & & & 0.2 & & & 0.71 & $0.07^{8}$ & 0.29 & & 0.64 & 0.43 & & 0.57 & 0.79 & 0.21 & & & & & 0.57 & 0.43 & & & 0.57 & 0.43 & 0.57 & & 0.43 & & 1.00 & & & & & & & 1.00 & & & 0.92 \\
\hline 25 & Can & 0.095 & 0.91 & & & 0.0 & & & 0.91 & & 0.32 & & 0.68 & 0.32 & & 0.68 & 0.82 & 0.14 & & 0.04 & & & 0.50 & 0.50 & & & 0.86 & 0.14 & 0.32 & & 0.68 & & 1.00 & & & & & & & 1.00 & & & 0.67 \\
\hline 26 & $\mathrm{Vlc}$ & $0.17^{8}$ & 0.83 & & & 0.2 & & & 0.79 & & 0.46 & & 0.54 & 0.04 & & 0.96 & 1.00 & & & & & & 0.25 & 0.75 & & & 0.75 & & 0.50 & & 0.50 & & 1.00 & & & & & & & 1.00 & & & 1.00 \\
\hline L. euro & opaeus (1) & (non-lber & erian) & & & & & & & & & & & & & & & & & & & & & & & & & & & & & & & & & & & & & & & & \\
\hline 27 & Pyr & & 1.00 & & & 0.0 & & & 0.94 & & 0.50 & & 0.50 & 0.38 & & 0.62 & 0.50 & 0.50 & & & & & 0.56 & 0.44 & & & 0.19 & 0.81 & 0.44 & & 0.56 & & 1.00 & & & & & & & 1.00 & & & \\
\hline 28 & Aus & & 1.00 & & & & & & 1.00 & & 0.07 & & 0.93 & 0.44 & & 0.56 & 0.56 & 0.44 & & & & & 0.19 & 0.81 & & & 0.56 & 0.44 & 0.62 & & 0.38 & & 1.00 & & & & & & $0.31^{t}$ & 0.69 & & & \\
\hline 29 & Ger & & 1.00 & & & 0.0 & & $0.04^{\prime}$ & 0.88 & & 0.33 & & 0.67 & 0.42 & & 0.58 & 0.58 & 0.42 & & & & & 0.54 & 0.46 & & & 0.46 & 0.54 & 0.22 & $0.05^{t}$ & 0.68 & & 1.00 & & & & & & $0.29^{t}$ & 0.71 & & & \\
\hline L. cast & troviejoi & & & & & & & & & & & & & & & & & & & & & & & & & & & & & & & & & & & & & & & & & & \\
\hline 30 & $\begin{array}{l}\text { Cas } \\
\text { didus }\end{array}$ & & & 1.0 & & & 1.00 & & & & & & 1.00 & & 1.00 & & & & $0.72 \quad 0.28^{8}$ & & & & & & & $0.11^{8}$ & 0.8 & 89 & 1.00 & & & & & & 1.00 & & 0.38 & & $0.06^{t}$ & & & & 0.11 \\
\hline $\begin{array}{l}\text { L. timi } \\
31\end{array}$ & idus & & & & 0.92 & 0.1 & & 0.85 & $0.04^{e}$ & & 0.31 & 0.69 & & $\begin{array}{ll}0.92 & 0.04\end{array}$ & & $0.04^{\circ}$ & & & & & & & & & & & 1.00 & & & & & & & 1.0 & & & & & 0.08 & $004^{\mathrm{e}}$ & 0.88 & & _ \\
\hline 32 & Swe & & 0.23 & & 0.77 & 0.3 & & 0.68 & & & 0.64 & 0.36 & & $\begin{array}{lll}0.82 & 0.14\end{array}$ & & $0.04^{\circ}$ & & & & & $\begin{array}{ll}0.95 & 0.05\end{array}$ & & $\begin{array}{ll}0.50 & 0.5\end{array}$ & & & & $\begin{array}{l}1.00 \\
\text { D }\end{array}$ & & 0.45 & 0.55 & & & & 0.95 & & 0.05 & & & 0.68 & 0.07 & 0.32 & & - \\
\hline
\end{tabular}

*from Melo-Ferreira et al. (2005) and Alves et al. (2008b); putative introgression of 'timidus, ${ }^{\circ}$ europaeus or ${ }^{8}$ granatensis origin is indicated in bold. 


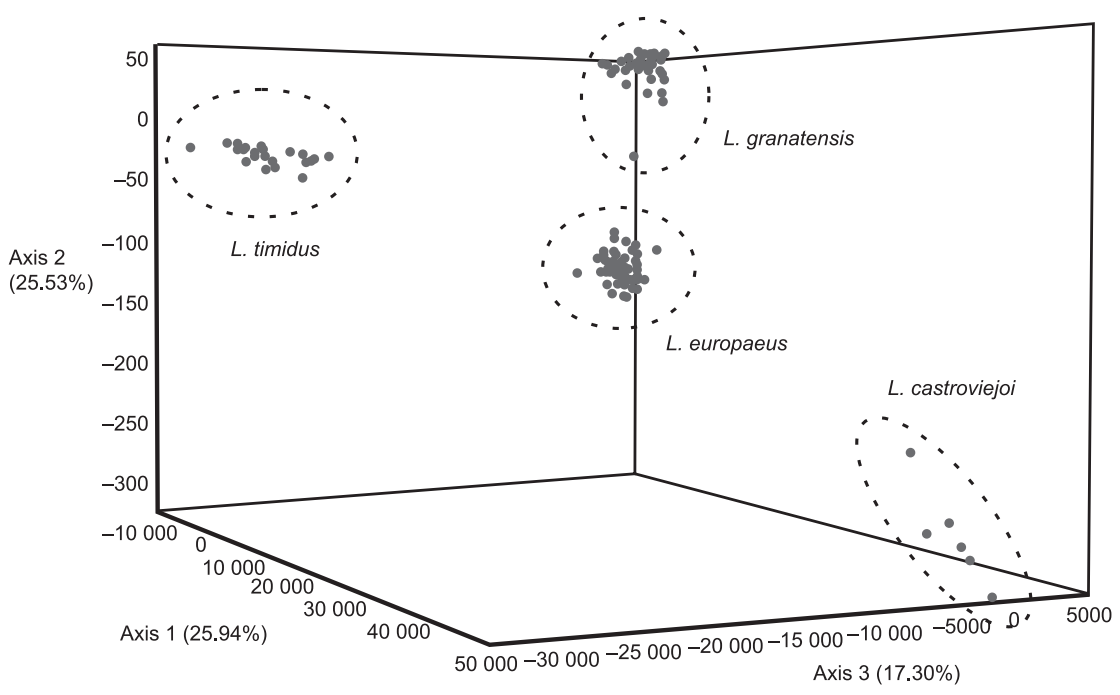

Fig. 2 Three-dimensional plot of the factorial correspondence analysis based on genotypic SNP data at 10 autosomal loci. Each dot represents one specimen, and the species envelopes are shown with dotted lines.
At six of these loci, the two species do not share any other allele (Table 2), the exception being TF. Note that most of these alleles are absent from Iberian L. europaeus, and therefore, cannot be considered to come from this species (Table 3). Overall there is, therefore, consistent evidence of sporadic but geographically widespread introgression from L. timidus into L. granatensis at six of the 10 autosomal loci (ALB, CA2, KTLG, OXA1L, SPTBN1 and UCP2). Conversely, however, none of the seven rare alleles of L. timidus is frequent in L. granatensis.

Eight alleles at seven loci occur only in the northernmost populations of L. granatensis, closest to the L. europaeus range (ALB_3,CA2_2,CA2_5, DARC_2, HPX_4, KITLG_1, OXA1L_2, UCP2_4, populations Ala1 and Nav1; Table 3), and also occur in L. europaeus, suggesting that they might have introgressed from the latter species into the former. Only one allele, SPTBN1_2, is frequent in L. europaeus, sporadic in L. granatensis but also frequent in L. timidus, and may, therefore, have originated from the latter species (see above). Introgression from L. granatensis into L. europaeus is logically suggested only in the Iberian range of the latter by the presence, at low frequencies, of five alleles that are mostly frequent in L. granatensis but rare or absent in L. timidus as well as in non-Iberian L. europaeus (ALB_1, CA2_2, DARC_1, KITLG_4 and UCP2_1; Table 3). Only CA2_2 is rare in L. granatensis and may represent introgression in the other direction. Therefore, overall geographically limited introgression from Iberian L. europaeus into L. granatensis may have affected seven of the 10 analysed loci (ALB, CA2, DARC, HPX, KITLG, UCP2 and OXA1L), and introgression in the other direction appears to have affected four of them (ALB, DARC, KITLG and UCP2).

Applying a similar reasoning to detect potential introgression from L. timidus into Iberian L. europaeus is not possible because the five alleles that are rare in this range of L. europaeus are absent or very rare in L. timidus. It is, however, remarkable that three alleles (CA2_4, TF_2 and UCP2_3; Table 3) are absent in Iberian L. europaeus, rare in non-Iberian L. europaeus, but frequent or fixed in L. timidus. Some introgression from L. europaeus into L. timidus populations (either Alps or Sweden) can also be suspected (ALB_3, CA2_5, HPX_4 and UCP2_4).

In L. castroviejoi, at eight of the 10 loci, the allele that is either fixed or most frequent in this species is absent from the other species. DARC_4 is fixed in L. castroviejoi and only found in one population of Iberian L.europaeus, but TF_1 is frequent in all species. Three of the rarer alleles in L. castroviejoi are very frequent in L. granatensis (KTLG_4, STPBN1_1, UCP2_1), from where they could therefore come.

At some loci, different species share alleles at high frequencies and we must examine whether this could result from introgression, which could thus be extensive. Of the 49 detected alleles in our experiment, only seven appeared shared among species with frequencies higher than $10 \%$ (DARC_2, HPX_1, PRKCI_2, PRKCI_3, SPTBN1_2, TF_1 and UCP2_1). This sharing may result from insufficient resolution of the SNPs genotyping methodology, as is obviously the case at locus TF for which only two SNPs were typed. In most loci mentioned above and most species pairs, massive introgression between species appears unlikely because only one of the two or three alleles present in any species is shared with the other member of the pair. However, there remains cases where we cannot reject the possibility that massive introgression occurred. At UCP2, allele 1 is almost fixed in L. granatensis and reaches a frequency of over $30 \%$ in L. castroviejoi, which may result from introgression. At PRKCI, the two alleles found in L. timidus are also found in L. granatensis, and therefore, massive introgression from the former into the latter cannot be dismissed.

Applying the individual genotype assignation method implemented in the software Structure (Pritchard et al. 


\begin{tabular}{|c|c|c|c|c|c|c|c|c|}
\hline \multirow[b]{2}{*}{ Sample } & \multirow[b]{2}{*}{$n$} & \multirow[b]{2}{*}{$l$} & \multicolumn{4}{|c|}{ Polymorphism } & \multicolumn{2}{|l|}{ Neutrality } \\
\hline & & & $h$ & $S$ & $\pi \%$ & $\theta \%$ & Tajima's $D$ & $\mathrm{Fu}^{\prime} \mathrm{s} F_{\mathrm{S}}$ \\
\hline \multicolumn{9}{|l|}{ MSN } \\
\hline gra & 21 & 1017 & 2 & 1 & $0.032(0.011)$ & $0.027(0.027)$ & 0.292 & 0.684 \\
\hline eur & 17 & 1014 & 3 & 4 & $0.103(0.036)$ & $0.117(0.068)$ & -0.360 & 1.156 \\
\hline cas & 2 & 1013 & 1 & 0 & 0.000 & 0.000 & - & - \\
\hline tim & 8 & 1014 & 3 & 4 & $0.127(0.052)$ & $0.152(0.095)$ & -0.763 & 0.671 \\
\hline \multicolumn{9}{|l|}{ SMCX } \\
\hline gra & 21 & 998 & 2 & 1 & $0.018(0.011)$ & $0.028(0.028)$ & -0.618 & -0.137 \\
\hline eur & 17 & 997 & 2 & 2 & $0.024(0.020)$ & $0.059(0.044)$ & -1.504 & 0.122 \\
\hline cas & 2 & 997 & 1 & 0 & 0.000 & 0.000 & - & - \\
\hline tim & 8 & 998 & 2 & 1 & $0.025(0.018)$ & $0.039(0.039)$ & -1.055 & -0.182 \\
\hline \multicolumn{9}{|l|}{ SRY } \\
\hline gra & 30 & 1687 & 3 & 2 & $0.030(0.005)$ & $0.030(0.022)$ & 0.015 & 0.067 \\
\hline eur & 22 & 1689 & 3 & 3 & $0.049(0.018)$ & $0.050(0.032)$ & -0.083 & 0.796 \\
\hline cas & 2 & 1687 & 1 & 0 & 0.000 & 0.000 & - & - \\
\hline tim & 24 & 1687 & 1 & 0 & 0.000 & 0.000 & - & - \\
\hline
\end{tabular}

Table 4 Polymorphism and neutrality tests for the sequenced sex chromosome loci

gra, Lepus granatensis; tim, Lepus timidus; eur, Lepus europaeus; cas, Lepus castroviejoi; $n$, sample size; 1 , length of the sequence (bp); $h$, number of haplotypes; $S$, number of segregating sites; $\pi$, nucleotide diversity; $\theta(\mathrm{s})$, computed from the number of segregating sites. Standard deviations are shown in brackets.

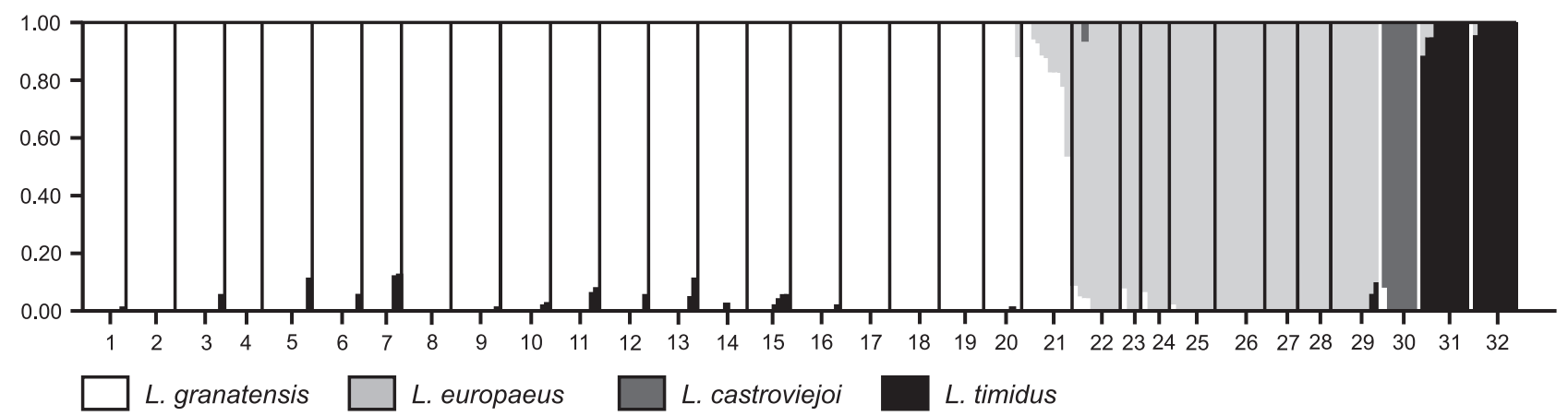

Fig. 3 Summary results of the analysis with Structure, based on the SNP haplotype data at 10 autosomal loci, with $K=4$ groups and the admixture model. Populations are numbered on the horizontal axis according to Table 1 and Fig. 1. Vertical bars give the estimated contribution of each of the four groups to the genotype of each individual, using the colour codes indicated in the legend.

$2000)$, in $100 \%$ of cases, conspecific individuals were classified together and have high posterior probabilities of belonging to their group (Fig. 3). There were, however, suggestions at low probability levels, of admixture between some of the species. An L. timidus contribution is suggested in 12 out of 21 L. granatensis populations. However, the $95 \%$ confidence interval of the associated probability excludes zero for only three specimens, from Pancas and Castelo Branco. Six L. granatensis from Álava and one from Navarra, the two populations very close to the border with L.europaeus, show significant signs of introgression from the latter species. None of the other instances of possible introgression is significant but their geographical distributions appear to sustain the introgression hypothesis, since potential traces of L. granatensis in L. europaeus are only found in the Iberian populations of this species. Introgression is also suggested to occur from L. granatensis into L. castroviejoi as well as between L. europaeus and L. timidus outside Iberia, from the latter to the former in Germany and in the opposite direction in the Alps and Sweden.

\section{Two centromeric X chromosome loci}

The alignment of the 48 sequences obtained for the Xlinked loci (GenBank Accession nos FJ811538-FJ811556) contained $992-1017 \mathrm{bp}$ in the case of MSN, defining nine haplotypes with 14 substitutions, and 983-997 bp for SMCX, defining seven haplotypes with 15 substitutions 


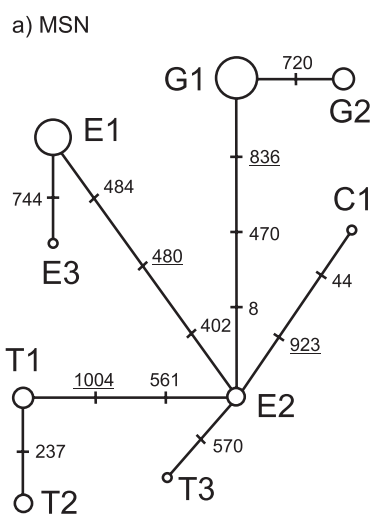

b) SMCX

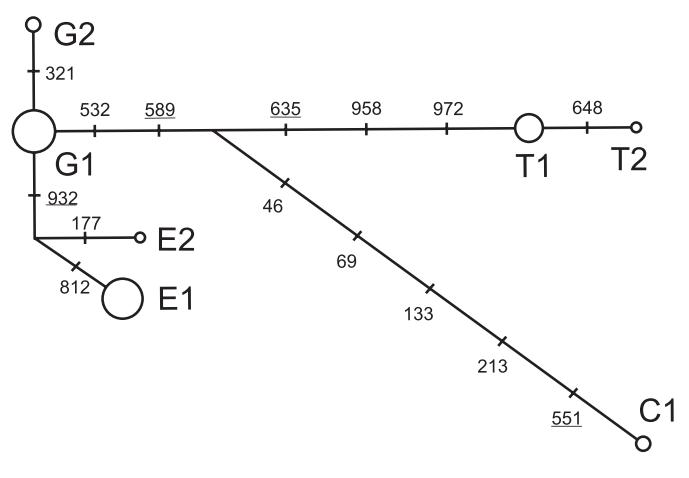

Fig. 4 Median-joining networks of the haplotypes detected at the X-linked loci, (a) MSN and (b) SMCX. Open circle sizes are proportional to haplotype frequencies, and the letter in haplotype names refers to the species first letter (G: L. granatensis; E: $L$. europaeus; C: L. castroviejoi; T: L. timidus). Positions of the mutations relative to the deposited sequences are given along the branches. Underlined positions are those used for SNP typing.
(Table 4). Three and two insertions/deletions were found, respectively, in MSN and SMCX (see Tables S14 and S15, Supporting information). Lepus timidus was the most variable species at these loci, followed by L. europaeus and L. granatensis, but no variation was detected in the poorly sampled L. castroviejoi. None of the neutrality tests performed was significant and no haplotype was shared between species. The genealogical relationships of haplotypes at these two loci could be unambiguously inferred in the absence of homoplasy (Fig. 4). While the results at locus SMCX were compatible with the monophyly of the four species, the data at MSN are insufficient to formally sustain it, but do not refute it either.

The SNP genotyping at the MSN (4 SNPs; Table S14) and SMCX (4 SNPs; Table S15) loci was retained in 353 specimens from the four species (241 L. granatensis, $79 \mathrm{~L}$. europaeus, 9 L. castroviejoi and 24 L. timidus; Table 1), after dismissing individuals with missing information. On this sample, the four SMCX haplotypes were almost completely diagnostic of the four species (Table 2). Introgression was detected in both directions between $L$. granatensis and $L$. europaeus which share alleles SMCX_1 and SMCX_2, but this concerns only the two populations from Álava, close to the contact between these species (Table 1; Table S16, Supporting information). Allele MSN_3 is shared at low frequencies between L. europaeus (specimens from Cantabria, Germany and Austria, Table S17, Supporting information) and L. timidus (from the Alps), but could be produced by either sequence haplotype E2 or T3, that our SNP assay does not discriminate. At this locus, one specimen of L. europaeus from Álava had allele MSN_1 that is fixed in L. granatensis, again suggesting exchange limited to the contact zone between these species.

\section{The Y chromosome}

Among the 78 specimens sequenced for SRY (see Table 1; Table S18, Supporting information), we observed seven different haplotypes (GenBank Accession nos FJ811530FJ811537), defined by nine substitutions and one insertion/

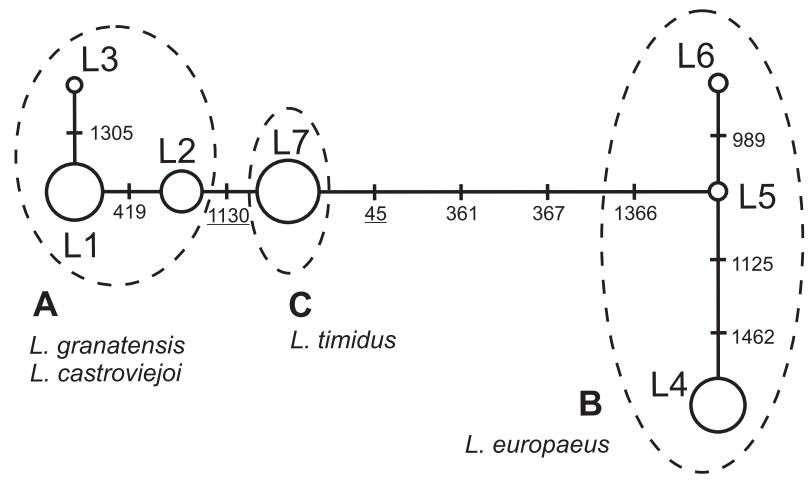

Fig. 5 Median-joining network relating the SRY sequence haplotypes found in this study (L1 to L7). The size of open circles is proportional to haplotype frequency. The mutational steps between haplotypes are represented by their nucleotide position relative to the sequences deposited in GenBank. The underlined numbers show the position of the polymorphic restriction sites. Dashed envelopes depict the groups of haplotypes discriminated in the PCR-RFLP assay (A, B and C), indicating the species where they were found.

deletion (Table 2; Fig. 5). Three haplotypes, L1 to L3, were found in L. granatensis (Table S19, Supporting information) while haplotypes L4 to L6 occurred in L. europaeus but only L4 was found in Iberia. A single haplotype (L7) was found in L. timidus despite significant sampling over most of the species range. Haplotype L2, widespread in L. granatensis, was detected in the two analysed $L$. castroviejoi specimens. Nucleotide diversity was slightly higher in L. europaeus than in L. granatensis (Table 4) and no diversity was found either in L. timidus or in L. castroviejoi.

The PCR-RFLP assay applied to $184 \mathrm{~L}$. granatensis, $44 \mathrm{~L}$. europaeus, 2 L. castroviejoi and 13 L. timidus allowed separating three groups of SRY haplotypes: sequence haplotypes L1 to L3 produced RFLP haplotype A; L5 to L7, RFLP haplotype B, and L7, RFLP haplotype C (Fig. 5; Table S19). L. granatensis, L. europaeus and L. timidus always displayed their own RFLP haplotype (A, B and C, respectively), and thus, no trace of interspecific exchange was detected among these species. The RFLP haplotype detected in 
L. castroviejoi is that present in L. granatensis (Table 2; Table S20, Supporting information, for detailed results).

\section{Discussion}

Comparing the degree of reticulation of mtDNA, which represents a single and easily characterized linkage group, to that of the immense and recombining nuclear genome may appear a difficult challenge, especially on non-model species whose genome sequence is not yet characterized. Therefore, although our approach involving a total of 13 nuclear genes on different chromosomes (autosomes, $\mathrm{X}$ and $\mathrm{Y}$ ) represents a notable effort, it can only deliver a glimpse at how the genomes of the four hare species studied here were affected by their past hybridization, resulting in the observed massive mtDNA introgression. For this reason, we attempted to select regions of the genome for which there were a priori reasons to suspect a co-evolution with mtDNA (which is why we included UCP2 and OXA1L, two nuclear genes involved in mitochondrial metabolism) or to predict contrasted patterns due to different modes of transmission and functional roles (a reason for choosing the sex chromosomes).

\section{Autosomal exchanges among species}

The extensive mtDNA introgression of Lepus timidus origin into the Iberian hare species might have induced cointrogression of nuclear genes involved in any aspect of mitochondrial physiology. However, the poor knowledge of the hare genome reduced the choice of genes that we were able to study. The physiological role of UCP2 is reported to include the regulation of insulin secretion and the protection against reactive oxidative damage (Echtay 2007), a property that could be linked with adaptation (Criscuolo et al. 2005). A role of this type is more difficult to infer in the case of OXA1L, known as a mitochondrial integral membrane protein required for the correct biogenesis of some components of the oxidative phosphorylation system complexes (Stiburek et al. 2007). However, these two genes were among the most discriminant among species, showing no evidence of substantial introgression from L. timidus into any of the three species present in Iberia.

Considering all autosomal loci and inspecting the alleles with extreme frequency differences between species, we drew conclusions concordant with those of the more formal individual assignation procedure. Introgression was detected in situations where it was anticipated (from L. timidus into L. granatensis) or geographically possible (between Iberian L. europaeus and L. granatensis as well as between non-Iberian L. europaeus and L. timidus). However, it was not suggested when geographically impossible, such as from L. granatensis into L. timidus, which is reassuring concerning the validity of the approach. The geographical distribution of alleles inferred as introgressed was an informative aspect of this part of the analysis. In L. granatensis, alleles of presumed L. timidus origin were distributed all over Iberia, and there was no tendency for them to be either more present nor more frequent in northern Iberia, as is the case for mtDNA of L. timidus origin (Melo-Ferreira et al. 2005). In contrast, alleles of L. europaeus origin were restricted to the populations closest to the contact with this species. There was also evidence of introgression in the other direction, from L. granatensis into Iberian L. europaeus, attesting to the existence of a hybrid zone between these two species, as confirmed by an independent study based on microsatellites (Freitas 2006). An unexpected result was the stronger suggestion of introgression from L. timidus into non-Iberian than into Iberian L. europaeus. Introgression between these two species appears to occur in both directions outside Iberia, in concordance with independent observations based on mtDNA (Thulin et al. 1997; Suchentrunk et al. 2005). The absence of autosomal L. timidus contribution to Iberian L. europaeus raises the possibility that no hybridization occurred between these species in Iberia. Then, the timidus mtDNA might have been captured by L. europaeus through hybridization with L. granatensis. This hypothesis has been previously raised (Melo-Ferreira et al. 2007) and deserves further investigation.

In summary, autosomal introgression from L. timidus into L. granatensis may have occurred at several loci, but is mostly sporadic and always spread over Iberia, in contrast to mtDNA introgression that is massive and more pronounced in the north. Massive introgression cannot be ruled out for PRKCI, and could be at frequencies comparable to those of mtDNA, but does not appear geographically structured over Iberia. On the contrary, there is surprisingly little evidence of autosomal introgression, whether sporadic or massive, from L. timidus into Iberian L. europaeus, which again is in contrast with mtDNA.

\section{No sex chromosome introgression from $\mathrm{L}$. timidus}

The SRY gene belongs to the nonrecombining part of the $Y$ chromosome and should faithfully trace patrilinear history without the complications of recombination. However, the SRY locus is known to occur in multiple copies in some rodent species (Nagamine 1994; Lundrigan \& Tucker 1997) and to be duplicated in rabbit (Geraldes 2006; Geraldes \& Ferrand 2006) and possibly in brown hares (Putze et al. 2007). Nevertheless, we obtained unique PCR products that produced clear sequences with variants that unambiguously identified species-specific lineages, and therefore, there is no reason to suspect that our conclusions were affected by the eventual presence of multiple copies of SRY.

The SRY haplotypes were all species-specific, with the exception of the single haplotype found in our limited 
sample of L. castroviejoi, which was identical to a frequent haplotype of $L$. granatensis. Although the phylogeny of hares is far from being resolved, none of the available data indicates a close phylogenetic relationship between $L$. castroviejoi and $L$. granatensis, either for mtDNA or nuclear genes (Alves et al. 2003, 2008a). Thus, whether resemblance between these species at SRY results from secondary exchange rather than shared ancestry is open and awaits a better resolution of the species phylogeny. This uncertainty does not affect the conclusion of an absence of $Y$ introgression from L. timidus into L. castroviejoi, since L. timidus is well characterized by a specific single haplotype. In fact, such absence of polymorphism at SRY over the range of the widely distributed L. timidus species is surprising. It contrasts with what we observed in L. granatensis and L. europaeus, and with the substantial mtDNA variability of the species (Melo-Ferreira et al. 2007). However, this single L. timidus haplotype was not found in any other species, indicating that $\mathrm{mtDNA}$ introgression was not paralleled by the $\mathrm{Y}$ in Iberia.

Our sequencing results on the two $X$ genes also indicate the absence of introgression from L. timidus into any of the three species from Iberia. The SNP data on a larger sample unambiguously confirmed this observation in the case of SMCX. The SNP assay for MSN was not completely diagnostic between L. timidus and L. europaeus, and a lowfrequency SNP haplotype was shared by these species. This is, however, unlikely to represent introgression, as could be checked by sequencing two of the specimens concerned that belonged to L. europaeus haplotype E2 and to L. timidus haplotype T3 (Fig. 4), that our SNP assay did not discriminate. Therefore, introgression of the $\mathrm{X}$ genes from $L$. timidus appears at most extremely limited, and most probably absent. The $X$ is predominantly maternally transmitted, and this is in contrast with the pervasive introgression of the maternally transmitted mtDNA. In keeping with the results on the autosomal SNPs and previous microsatellite data (Freitas 2006), limited exchange of $X$ genes between L. granatensis and L. europaeus in the contact zone was detected.

\section{Reconciling the data}

In order to account for the massive mtDNA introgression in Iberian hares, we previously considered a scenario of competitive replacement with hybridization: L. timidus being overtaken by $L$. granatensis in central Iberia and by $L$. europaeus in northern Iberia when the climate warming favoured these latter species at the end of the last glacial period (Melo-Ferreira et al. 2007). The sole hypothesis of competitive replacement would predict a similar pattern for the whole genome, notwithstanding random fluctuations between genomic regions. Other studies have described a contrast between the pervasiveness of mtDNA introgression and the limited or undetectable introgression of nuclear genes (e.g. Roca et al. 2005; Bachtrog et al. 2006; Berthier et al. 2006). Several sources of gender asymmetries in the reproductive and demographic processes may contribute to such patterns. One such asymmetry is higher male-biased dispersal which may be a rather general pattern in mammals (see Lawson Handley \& Perrin 2007 for a recent review). A greater propensity of males to pioneer intrusions into territories occupied by another species would favour an initial asymmetry of hybridization and would contribute to erase traces of introgression of male-transmitted parts of the genome, by a continuous influx from the pure parental populations. It would also contribute to spread introgressed male-transmitted genes into the native territory of the invading species, and this could account for the widespread distribution of introgressed alleles that we inferred. Sex-biased dispersal has been investigated in a few species of hares and the results are somewhat ambiguous. While no clear evidence for such a pattern has been found in some studies of L. americanus and L. europaeus (Gilles \& Krebs 1999; Bray et al. 2007), others reported a tendency for malebiased dispersal in the latter species and in L. timidus (Fickel et al. 2005; Hamill et al. 2007). Whether dispersal is male-biased in L. granatensis remains to be assessed.

The prevalence of mtDNA introgression could reflect a propensity of female L. timidus to mate with heterospecific males. Male competition has been suggested to explain asymmetric patterns of introgression (e.g. Roca et al. 2005; Pidancier et al. 2006). Also, in Sweden, mtDNA introgression of local L. timidus into recently introduced L. europaeus was found but not the reverse (Thulin et al. 1997), which was suggested to result from the dominance of the larger europaeus over the smaller timidus males (Thulin \& Tegelström 2002). However, reciprocal mtDNA exchanges between these species have recently been reported in Russia (Thulin et al. 2006) and in the Alps (Suchentrunk et al. 2005). In addition, larger male dominance hardly explains the interaction between L. timidus and L. granatensis, since the latter species is generally smaller (Alves \& Niethammer 2003).

Another gender asymmetry may lie in reproductive behaviour. In most species, levels of investment of the two parents in reproduction are correlated with their respective choosiness for partners (for general references see Chan \& Levin 2005). The general idea suggested by Wirtz (1999) and formalized by Chan \& Levin (2005) in the case of interspecific contact, involves frequency-dependent assortative mating of females in zones of sympatry where one species is more abundant. It is hypothesized that females of the rarer species often fail to encounter a conspecific male partner and end up mating with a male from the other, more abundant, species. Successive backcrossing with the same frequency-dependent asymmetry could favour preferential introgression of the maternally transmitted mtDNA of the 
rarer species into the more abundant one. However, the situation modelled by Chan \& Levin (2005) concerns a single population in a condition of sympatry, while the likely history of hares in Iberia is that of an invasion of the temperate species into the territory occupied by L. timidus (MeloFerreira et al. 2007). Applying this reasoning to the case of hares would imply that introgression occurred when the temperate species became more abundant than the arctic one in zones of temporary sympatry. Modelling of the more complex process of invasion of one species into the territory occupied by another by serial colonization has suggested that the stage that determines the magnitude of the introgression is hybridization in territories where the invading species is still comparatively rare (Klopfstein et al. 2006; Currat et al. 2008). Rare hybridization may then lead to appreciable frequencies of introgressed alleles that will thus have more chance to spread as the front of expansion of the invasive species progresses. Further investigations would be necessary to appreciate the exact conditions of relative abundances of the two species under which female frequency-dependent assortative mating is likely to play a role, under a geographically structured model of invasion of one species into the territory of another. Currat et al. (2008) argue that lower migration rate of mtDNA (due to female transmission, potentially coupled with lower female migration) could suffice to predict more introgression of mtDNA than of the rest of the genome, because traces of initial introgression would be more slowly erased by intraspecific gene flow from non-introgressed populations. However, in the case of hares, the contrast is pronounced relative to the autosomes and extreme in the case of the sex-chromosomes.

A potential source of impediment of introgression of genes is their involvement in reproductive isolation. In house mice and rabbits, the absence of $\mathrm{Y}$ chromosome introgression across hybrid zones between subspecies is suggestive of selection against hybrid males (Vanlerberghe et al. 1988; Tucker et al. 1992; Dod et al. 1993; Geraldes et al. 2006, 2008), in conformity with Haldane's rule (Haldane 1922). The $Y$ has been often shown to be less prone to introgress than mtDNA, presumably because of its involvement in selection linked to reproduction (Tosi et al. 2000; Ermakov et al. 2006; Pidancier et al. 2006). The absence of Y flow may also result from its direct role in hybrid incompatibility (e.g. Mishra \& Singh 2005). However, the frequencydependent female assortative mating process that we invoked could alone explain the absence of $Y$ chromosome introgression. Nevertheless, hybrid incompatibility (affecting hybrid males in order to be compatible with the extensive mtDNA introgression) may be necessary to account for the absence of $X$ introgression. An important role of the $X$ chromosome in hybrid unfitness has been reported for instance in Drosophila (Masly \& Presgraves 2007; Presgraves 2008; and references therein) or mice (Zechner et al. 1996; Oka et al. 2004; Storchová et al. 2004; Britton-Davidian et al. 2005; Good et al. 2008). Patterns of limited X introgression in hybrid zones between subspecies of house mouse (Tucker et al. 1992; Dod et al. 1993; Payseur et al. 2004) or rabbit (Geraldes et al. 2006) also provide indirect evidence for this phenomenon. The total absence of $\mathrm{Y}$ chromosome introgression we found here could then be an indication that the X chromosome is involved in hybrid male unfitness among these species. The presumption that the MSN and SMCX genes are linked to hybrid incompatibility factors is reinforced by their lying in the centromeric region of the $\mathrm{X}$ chromosome, a region of supposedly low recombination. This is based on the rabbit genetic map (ChantryDarmon et al. 2003) but given the synteny of these genes between rabbit and humans, they are most probably also $X$ centromeric in hares. Theoretical predictions and empirical verifications have indicated that genetic factors responsible for interspecific isolation are likely to lie in regions of low recombination (Noor et al. 2001; Rieseberg 2001; Navarro \& Barton 2003; Carneiro et al. 2009). In the European rabbit, introgression between the two subspecies was shown to be extremely reduced for SMCX and MSN when compared to loci in the highly recombining telomeric region (Geraldes et al. 2006).

\section{Conclusion}

We found a striking contrast between the pervasiveness of L. timidus mtDNA in three species of hares, the mostly sporadic or undetectable introgression of 10 autosomal genes and its complete absence for the sex chromosomes. The idea that mtDNA introgression results from the invasion of the temperate species into the territory of L. timidus during climate warming appears logical and plausible. However, the complete absence of sex chromosome introgression in the face of such a massive one for mtDNA suggests that strong gender-related asymmetries were involved, and that they must correspond to rather generic biological processes since they have prevailed in the three species of Iberian hares independently. Frequency-dependent female assortative mating could be such a general process, but the conditions under which it could produce the contrast between mtDNA and the autosomes remain to be assessed. Higher male dispersal appears more likely to account for geographically limited mtDNA introgression in L. granatensis as well as species-wide traces of autosomal introgression. The absence of $\mathrm{X}$ and $\mathrm{Y}$ introgression is evocative of another general phenomenon, the frequent and strong involvement of the $X$ in hybrid male sterility. It could be that a combination of these factors has contributed to the observed contrasted pattern. Finally, although we have here been looking for generic factors that could explain the contrasting patterns of introgression through different genomic regions, the possibility that, in 
the particular case of hares, introgression of L. timidus mtDNA was favoured by natural selection cannot be dismissed and should be tested by other means.

\section{Acknowledgements}

Financial support was partially obtained from the Portuguese Fundação para a Ciência e a Tecnologia (projects PPCDT/BIA-BDE/ 58817/2004 and PTDC/BIA-BDE/72277/2006, and SFRH/BD/ 13160/2003 PhD grant and SFRH/BPD/43264/2008 post-doc grant to J.M.F.). We thank Ibon Telletxea, Christian Gortazar, Rafael Villafuerte, Alexei Kryukov, Ettore Randi and Franz Suchentrunk for providing samples. We thank Armando Geraldes, Pedro J. Esteves and Catarina Carmo for providing us unpublished primers and sequences. DNA sequencing and $\mathrm{SNaPshot} \mathrm{genotyping} \mathrm{was}$ performed on the platform of IFR119 ('Montpellier Environnement Biodiversité'). This is contribution ISEM-2009-031.

\section{References}

Altuna J (1970) Hallazgo de una liebre artica (Lepus timidus) en el yacimiento prehistorico de Urtiga (Guipuzcoa). Munibe, 22, 165-168. Alves PC, Niethammer J (2003) Die iberischen Hasen. In: Handbuch der Säugetiere Europas (eds Niethammer J, Krapp F), pp. 137-154. Aula-Verlag, Vienna, Austria.

Alves PC, Ferrand N, Suchentrunk F, Harris DJ (2003) Ancient introgression of Lepus timidus mtDNA into L. granatensis and L. europaeus in the Iberian Peninsula. Molecular Phylogenetics and Evolution, 27, 70-80.

Alves PC, Melo-Ferreira J, Branco M et al. (2008a) Evidence for genetic similarity of two allopatric European hares (Lepus corsicanus and L. castroviejoi) inferred from nuclear DNA sequences. Molecular Phylogenetics and Evolution, 46, 1191-1197.

Alves PC, Melo-Ferreira J, Freitas H, Boursot P (2008b) The ubiquitous mountain hare mitochondria: multiple introgressive hybridization in hares, genus Lepus. Philosophical Transactions of the Royal Society B: Biological Sciences, 363, 2831-2839.

Angerbjörn A, Flux J (1995) Lepus timidus. Mammalian Species, 495, $1-11$.

Arnold ML, Sapir Y, Martin NH (2008) Genetic exchange and the origin of adaptations: prokaryotes to primates. Philosophical Transactions of the Royal Society B: Biological Sciences, 363, 2813-2820.

Bachtrog D, Thornton K, Clark A, Andolfatto P (2006) Extensive introgression of mitochondrial DNA relative to nuclear genes in the Drosophila yakuba species group. Evolution, 60, 292-302.

Belkhir K, Borsa P, Chikhi L, Raufaste N, Bonhomme F (1996-2004) Genetix 4.05 logiciel sous Windows, pour la génétique des populations. Laboratoire Génome Populations, Interactions: CNRS UMR 5171, Université de Montpellier II, Montpellier, France.

Berthier P, Excoffier L, Ruedi M (2006) Recurrent replacement of mtDNA and cryptic hybridization between two sibling bat species Myotis myotis and Myotis blythii. Proceedings of the Royal Society B: Biological Sciences, B273, 3101-3109.

Bray Y, Devillard S, Marboutin E, Mauvy B, Peroux R (2007) Natal dispersal of European hare in France. Journal of Zoology, 273, 426-434.

Britton-Davidian J, Fel-Clair F, Lopez J, Alibert P, Boursot P (2005) Postzygotic isolation between the two European subspecies of the house mouse: estimates from fertility patterns in wild and laboratory-bred hybrids. Biological Journal of the Linnean Society, 15, 379-393.
Carneiro M, Ferrand N, Nachman MW (2009) Recombination and speciation: loci near centromeres are more differentiated than loci near telomeres between subspecies of the European Rabbit (Oryctolagus cuniculus). Genetics, 181, 593-606.

Chan KM, Levin SA (2005) Leaky prezygotic isolation and porous genomes: rapid introgression of maternally inherited DNA. Evolution, 59, 720-729.

Chantry-Darmon C, Rogel-Gaillard C, Bertaud M et al. (2003) 133 new gene localizations on the rabbit cytogenetic map. Cytogenetic and Genome Research, 103, 192-201.

Criscuolo F, Gonzalez-Barroso MD, Bouillaud F et al. (2005) Mitochondrial uncoupling proteins: new perspectives for evolutionary ecologists. The American Naturalist, 166, 686-699.

Currat M, Ruedi M, Petit RJ, Excoffier L (2008) The hidden side of invasions: massive introgression by local genes. Evolution, 62, 1908-1921.

Dod B, Jermiin LS, Boursot P et al. (1993) Counterselection on sex chromosomes in the Mus musculus European hybrid zone. Journal of Evolutionary Biology, 6, 529-546.

Echtay KS (2007) Mitochondrial uncoupling proteins - what is their physiological role? Free Radical Biology and Medicine, 43, 1351-1371.

Ermakov OA, Surin VL, Titov SV, Zborovsky SS, Formozov NA (2006) A search for Y-chromosomal species-specific markers and their use for hybridization analysis in ground squirrels (Spermophilus: Rodentia, Sciuridae). Russian Journal of Genetics, 42, 429-438.

Excoffier L, Laval G, Schneider S (2005) Arlequin, version 3.0: an integrated software package for population genetics data analysis. Evolutionary Bioinformatics Online, 1, 47-50.

Fickel J, Schmidt A, Putze M et al. (2005) Genetic structure of populations of European brown hare: Implications for management. Journal of Wildlife Management, 69, 760-770.

Flux JEC, Angermann R (1990) The hares and jackrabbits. In: Rabbits, Hares and Pikas. Status Survey and Conservation Action Plan (eds A Cj, JEC Flux). International Union for the Conservation of Nature and Natural Resources, Gland, Switzerland.

Freitas H (2006) Natural hybridization between the Iberian hare (Lepus granatensis) and the brown hare (L. europaeus) in northern Iberian Peninsula. MSc Thesis, Faculdade de Ciências da Univesidade do Porto, Porto, Portugal.

Fu YX (1997) Statistical tests of neutrality of mutations against population growth, hitchhiking and background selection. Genetics, 147, 915-925.

Geraldes A (2006) Evolutionary Genetics and Incipient Speciation in the European Rabbit (Oryctolagus cuniculus). PhD Thesis, Faculdade de Ciências da Universidade do Porto, Porto, Portugal.

Geraldes A, Carneiro M, Delibes-Mateos M et al. (2008) Reduced introgression of the $\mathrm{Y}$ chromosome between subspecies of the European rabbit (Oryctolagus cuniculus) in the Iberian Peninsula. Molecular Ecology, 17, 4489-4499.

Geraldes A, Ferrand N (2006) A 7-bp insertion in the 3' untranslated region suggests the duplication and concerted evolution of the rabbit SRY gene. Genetics Selection and Evolution, 38, 313320.

Geraldes A, Rogel-Gaillard C, Ferrand N (2005) High levels of nucleotide diversity in the European rabbit (Oryctolagus cuniculus) SRY gene. Animal Genetics, 36, 349-351.

Geraldes A, Ferrand N, Nachman MW (2006) Contrasting patterns of introgression at $\mathrm{X}$-linked loci across the hybrid zone between subspecies of the European rabbit (Oryctolagus cuniculus). Genetics, 173, 919-933. 
Gilles EA, Krebs CJ (1999) Natal dispersal of snowshoe hares during a cyclic population increase. Journal of Mammalogy, 80, 933-939.

Gompert Z, Forister ML, Fordyce JA, Nice CC (2008) Widespread mito-nuclear discordance with evidence for introgressive hybridization and selective sweeps in Lycaeides. Molecular Ecology, $17,5231-5244$

Good JM, Handel MA, Nachman MW (2008) Asymmetry and polymorphism of hybrid male sterility during the early stages of speciation in house mice. Evolution, 62, 50-65.

Haldane JBS (1922) Sex ratio and unisexual sterility of hybrid animals. Journal of Genetics, 12, 101-109.

Hamill RM, Doyle D, Duke EJ (2006) Spatial patterns of genetic diversity across European subspecies of the mountain hare, Lepus timidus L. Heredity, 97, 355-365.

Hamill RM, Doyle D, Duke EJ (2007) Microsatellite analysis of mountain hares (Lepus timidus hibernicus): Low genetic differentiation and possible sex-bias in dispersal. Journal of Mammalogy, $\mathbf{8 8}$.

Klopfstein S, Currat M, Excoffier L (2006) The fate of mutations surfing on the wave of a range expansion. Molecular Biology and Evolution, 23, 482-490.

Lawson Handley LJ, Perrin N (2007) Advances in our understanding of mammalian sex-biased dispersal. Molecular Ecology, 16, 1559-1578.

Lopez-Martinez N (1980) Les lagomorphs (Mammalia) du pléistocène supérieur de Jaurens. Nouvelles Archives Du Museum d'Histoire Naturelle de Lyon, 18, 5-16.

Lundrigan BL, Tucker PK (1997) Evidence for multiple functional copies of the male sex-determining locus Sry, in African murine rodents. Journal of Molecular Evolution, 45, 60-65.

Masly JP, Presgraves DC (2007) High-resolution genome-wide dissection of the two rules of speciation in Drosophila. Public Library of Science, Biology, 5, e243.

Matthee CA, van Vuuren BJ, Bell D, Robinson TJ (2004) A molecular supermatrix of the rabbits and hares (Leporidae) allows for the identification of five intercontinental exchanges during the Miocene. Systematic Biology, 53, 433-447.

McGuire JA, Linkem CW, Koo MS et al. (2007) Mitochondrial introgression and incomplete lineage sorting through space and time: phylogenetics of crotaphytid lizards. Evolution, 61, 28792897.

Melo-Ferreira J, Boursot P, Suchentrunk F, Ferrand N, Alves PC (2005) Invasion from the cold past: extensive introgression of mountain hare (Lepus timidus) mitochondrial DNA into three other hare species in northern Iberia. Molecular Ecology, 14, 2459-2464.

Melo-Ferreira J, Boursot P, Randi E et al. (2007) The rise and fall of the mountain hare (Lepus timidus) during Pleistocene glaciations: expansion and retreat with hybridization in the Iberian Peninsula. Molecular Ecology, 16, 605-618.

Mishra PK, Singh BN (2005) Why hybrid males are sterile in Drosophila? Current Science, 89, 1813-1819.

Mitchell-Jones A, Amori G, Bogdanowicz W et al. (1999) Atlas of European Mammals. Academic Press, London.

Nagamine CM (1994) The testis-determining gene, $S R Y$, exists in multiple copies in Old World rodents. Genetical Research, 64, 151-159.

Navarro A, Barton NH (2003) Accumulating postzygotic isolation genes in parapatry: a new twist on chromosomal speciation. Evolution, 57, 447-459.

Nielsen R (2005) Molecular signatures of natural selection. Annual Review of Genetics, 39, 197-218.
Noor MA, Grams KL, Bertucci LA, Reiland J (2001) Chromosomal inversions and the reproductive isolation of species. Proceedings of the National Academy of Sciences, USA, 98, 12084-12088.

Oka A, Mita A, Sakurai-Yamatani N et al. (2004) Hybrid breakdown caused by substitution of the $\mathrm{X}$ chromosome between two mouse subspecies. Genetics, 166, 913-924.

Payseur BA, Krenz JG, Nachman MW (2004) Differential patterns of introgression across the $\mathrm{X}$ chromosome in a hybrid zone between two species of house mice. Evolution, 58, 2064-2078.

Pidancier N, Jordan S, Luikart G, Taberlet P (2006) Evolutionary history of the genus Capra (Mammalia, Artiodactyla): discordance between mitochondrial DNA and Y-chromosome phylogenies. Molecular Phylogenetics and Evolution, 40, 739-749.

Pilkington MM, Wilder JA, Mendez FL et al. (2008) Contrasting signatures of population growth for mitochondrial DNA and $Y$ chromosomes among human populations in Africa. Molecular Biology and Evolution, 25, 517-525.

Plotner J, Uzzell T, Beerli P et al. (2008) Widespread unidirectional transfer of mitochondrial DNA: a case in western Palaearctic water frogs. Journal of Evolutionary Biology, 21, 668-681.

Presgraves DC (2008) Sex chromosomes and speciation in Drosophila. Trends in Genetics, 24, 336-343.

Pritchard JK, Stephens M, Donnelly P (2000) Inference of population structure using multilocus genotype data. Genetics, 155, 945-959.

Putze M, Nürnberg S, Fickel J (2007) Y-chromosomal markers for the European brown hare (Lepus europaeus, Pallas 1778). European Journal of Wildlife Research, 53, 257-264.

Rieseberg LH (2001) Chromosomal rearrangements and speciation. Trends in Ecology \& Evolution, 16, 351-358.

Roca AL, Georgiadis N, O'Brien SJ (2005) Cytonuclear genomic dissociation in African elephant species. Nature Genetics, 37, 96-100.

Rozas J, Sánchez-Delbarrio JC, Messeguer X, Rozas R (2003) DnaSP, DNA polymorphism analyses by the coalescent and other methods. Bioinformatics, 19, 2496-2497.

Sambrook E, Fritsch F, Maniatis T (1989) Molecular Cloning. Cold Spring Harbor Press, Cold Spring Harbor, New York.

Stephens M, Scheet P (2005) Accounting for decay of linkage disequilibrium in haplotype inference and missing data imputation. American Journal of Human Genetics, 76, 449-462.

Stephens M, Smith NJ, Donnelly P (2001) A new statistical method for haplotype reconstruction from population data. American Journal of Human Genetics, 68, 978-989.

Stiburek L, Fornuskova D, Wenchich L et al. (2007) Knockdown of human Oxa1l impairs the biogenesis of F1Fo-ATP synthase and NADH: ubiquinone oxidoreductase. Journal of Molecular Biology, 374, 506-516.

Storchová R, Gregorová S, Buckiová Det al. (2004) Genetic analysis of X-linked hybrid sterility in the house mouse. Mammalian Genome, 15, 515-524.

Suchentrunk F, Mamuris Z, Stamatis C et al. (2005) Introgressive hybridization in wild living mountain hares (L. timidus varronis) and brown hares (L. europaeus) and morphological consequences. Mammalian Biology, 70(Supplement), 39-40.

Tajima F (1989) The effect of change in population-size on DNA polymorphism. Genetics, 123, 597-601.

Takahata N, Slatkin M (1984) Mitochondrial gene flow. Proceedings of the National Academy of Sciences, USA, 81, 1764-1767.

Thompson JD, Higgins DG, Gibson TJ (1994) ClustalW: improving the sensitivity of progressive multiple sequence alignment through sequence weighting, position-specific gap penalties and weight matrix choice. Nucleic Acids Research, 22, 4673-4680. 
Thulin CG, Tegelström H (2002) Biased geographical distribution of mitochondrial DNA that passed the species barrier from mountain hares to brown hares (genus Lepus): an effect of genetic incompatibility and mating behaviour? Journal of Zoology, 258, 299-306.

Thulin CG, Jaarola M, Tegelstrom H (1997) The occurrence of mountain hare mitochondrial DNA in wild brown hares. Molecular Ecology, 6, 463-467.

Thulin CG, Fang M, Averianov AO (2006) Introgression from Lepus europaeus to L. timidus in Russia revealed by mitochondrial single nucleotide polymorphisms and nuclear microsatellites. Hereditas, 143, 68-76.

Tosi AJ, Morales JC, Melnick DJ (2000) Comparison of Y chromosome and mtDNA phylogenies leads to unique inferences of macaque evolutionary history. Molecular Phylogenetics and Evolution, 17, 133-144.

Tucker PK, Sage RD, Warner J, Wilson AC, Eicher EM (1992) Abrupt cline for sex chromosomes in a hybrid zone between two species of mice. Evolution, 46, 1146-1163.

Vanlerberghe F, Boursot P, Nielsen JT, Bonhomme F (1988) A steep cline for mitochondrial DNA in Danish mice. Genetic Research, 52, 185-193.

Wallner B, Huber S, Achmann R (2001) Non-invasive PCR sexing of rabbits (Oryctolagus cuniculus) and hares (Lepus europaeus). Mammalian Biology, 66, 190-192.

Wirtz P (1999) Mother species-father species: unidirectional hybridization in animals with female choice. Animal Behaviour, $58,1-12$.

Zechner U, Reule M, Orth A et al. (1996) An X-chromosome linked locus contributes to abnormal placental development in mouse interspecific hybrids. Nature Genetics, 12, 398-403.

J. Melo-Ferreira has been investigating phylogeography and introgression in hares and is interested in understanding the consequences of hybridization and adaptive evolution. P. C. Alves is a researcher at CIBIO, University of Porto, and his main research area is conservation genetics and evolution of Iberian mammals, particularly Lagomorphs. H. Freitas developed his MSc on the study of hybridization among hares. N. Ferrand heads the CIBIO, University of Porto, and is interested in a variety of questions in evolutionary and conservation genetics. P. Boursot has general interests in molecular evolution, hybridization and speciation and his favourite model is mice.

\section{Supporting information}

Additional supporting information may be found in the online version of this article:

Table S1 Primers used to amplify and sequence the 10 autosomal loci for SNP discovery.

Table S2 List of the loci analysed in this study, PCR conditions and primers used for either sequencing, SNaPshot or RFLP typing.
Table S3 SNaPshot primers and detected polymorphisms

Table S4 Sequence polymorphism and genotyped SNPs (A to D) of autosomal locus 1, ALB

Table S5 Sequence polymorphism and genotyped SNPs (A to D) of autosomal locus 2, CA2

Table S6 Sequence polymorphism and genotyped SNPs (A to D) of autosomal locus 3, DARC

Table S7 Sequence polymorphism and genotyped SNPs (A to C) of autosomal locus 4, HPX

Table S8 Sequence polymorphism and genotyped SNPs (A to D) of autosomal locus 5, KITLG

Table S9 Sequence polymorphism and genotyped SNPs (A to D) of autosomal loci 6, PRKCI

Table S10 Sequence polymorphism and genotyped SNPs (A to C) of autosomal locus 7, SPTBN1

Table S11 Sequence polymorphism and genotyped SNPs (A and B) of autosomal locus 8 , TF

Table S12 Sequence polymorphism and genotyped SNPs (A to C) of autosomal locus 9, OXA1L

Table S13 Sequence polymorphism and genotyped SNPs (A to D) of autosomal locus 10, UCP2

Table S14 Sequence polymorphism and genotyped SNPs (A to D) of the X-linked locus MSN

Table S15 Sequence polymorphism and genotyped SNPs (A to D) of the X-linked locus SMCX

Table S16 Absolute frequencies of the SMCX sequence and SNP haplotypes per analysed population.

Table S17 Absolute frequencies of the MSN sequence and SNP haplotypes per analysed population.

Table S18 Sequence polymorphism and typed SNPs (A and B) of the SRY locus

Table S19 HpyCH4III restriction sites (asterisks) for SRY RFLP haplotypes detected in four different hare species in Europe

Table S20 Absolute frequencies of the SRY sequence and RFLP haplotypes per analysed population. 